\title{
Profiling the resting venom gland of the scorpion Tityus stigmurus through a transcriptomic survey
}

\author{
Diego D Almeida', Katia C Scortecci², Leonardo S Kobashi ${ }^{2}$, Lucymara F Agnez-Lima², Silvia R B Medeiros², \\ Arnóbio A Silva-Junior ${ }^{1}$, Inácio de L M Junqueira-de-Azevedo ${ }^{3}$ and Matheus de F Fernandes-Pedrosa ${ }^{1 *}$
}

\begin{abstract}
Background: The scorpion Tityus stigmurus is widely distributed in Northeastern Brazil and known to cause severe human envenoming, inducing pain, hyposthesia, edema, erythema, paresthesia, headaches and vomiting. The present study uses a transcriptomic approach to characterize the gene expression profile from the non-stimulated venom gland of Tityus stigmurus scorpion.
\end{abstract}

Results: A cDNA library was constructed and 540 clones were sequenced and grouped into 153 clusters, with one or more ESTs (expressed sequence tags). Forty-one percent of ESTs belong to recognized toxin-coding sequences, with transcripts encoding antimicrobial toxins (AMP-like) being the most abundant, followed by alfa KTx- like, beta KTx-like, beta NaTx-like and alfa NaTx-like. Our analysis indicated that 34\% of the transcripts encode "other possible venom molecules", which correspond to anionic peptides, hypothetical secreted peptides, metalloproteinases, cystein-rich peptides and lectins. Fifteen percent of ESTs are similar to cellular transcripts. Sequences without good matches corresponded to $11 \%$.

Conclusions: This investigation provides the first global view of gene expression of the venom gland from Tityus stigmurus under resting conditions. This approach enables characterization of a large number of venom gland component molecules, which belong either to known or non yet described types of venom peptides and proteins from the Buthidae family.

\section{Background}

Scorpion morphology has changed little over the last four hundred million years. In the other hand, they naturally developed venom glands as a special weapon used in prey and defense. Tityus stigmurus belongs to the Buthidae family, widely distributed around the world and comprising all the species considered of medical interest [1]. In Brazil, scorpions from the genus Tityus are responsible for most reported envenomation accidents, primarily Tityus serrulatus, Tityus stigmurus and Tityus bahiensis [2]. T. stigmurus is the main causal agent of scorpionism in the Northeast; its envenomation is often characterized by local symptoms, such as: pain (94.4\%), hyposthesia (30\%), edema (17.8\%), erythema (17.8\%) and paresthesia (15.6\%) [3]. Nishikawa [4]

\footnotetext{
* Correspondence: mpedrosa@ufrnet.br

${ }^{1}$ Laboratório de Tecnologia e Biotecnologia Farmacêutica, Universidade Federal do Rio Grande do Norte, Av. Gal. Cordeiro de Farias, s/n, CEP 59010-180 Natal, $\mathrm{RN}$, Brazil

Full list of author information is available at the end of the article
}

reported that $T$. stigmurus venom is the most toxic $\left(\mathrm{DL}_{50}=0.773 \mathrm{mg} / \mathrm{kg}\right)$ when compared to $T$. serrulatus and T. bahiensis. Nevertheless, T. serrulatus is the only species that has been significantly studied.

In addition to their clinical relevance, scorpion venoms are known to contain a very complex mixture of biologically active compounds [5]. Of these, neurotoxins are the most studied and play a key role in the pathogenesis of scorpionism. These toxins are small peptides that interact with several types of ion channels, modifying the electrical activity of excitable cells [6]. The most widely known ion channels recognized by these molecules are $\mathrm{Na}^{+}$channels [7], $\mathrm{K}^{+}$channels [8], ryanodine sensitive $\mathrm{Ca}^{2+}$ channels [9], T-type $\mathrm{Ca}^{2+}$ channels $[10,11]$ and $\mathrm{Cl}^{-}$channels [12]. Their properties make these peptides useful as molecular and pharmacological tools for studying ion channels. Another noteworthy class of molecules present in the venom gland are antimicrobial peptides, which may be involved in ancient innate immunity [13]. There are an estimated 150,000 distinct polypeptides

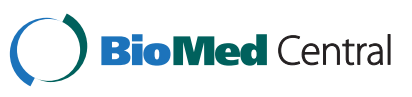


found in the approximately 1500 known scorpion species worldwide [14], representing a broad scope for drug research and development.

The venoms of $T$. stigmurus, $T$. serrulatus and $T$. bahiensis have similar toxic components and display a high degree of cross reactivity between specific antiserums [15-18]. Earlier studies reported the sequence of some $T$. stigmurus toxins, homologous to the previously known gama, III-8 and IV-5 toxins from $T$. serrulatus. These were named Tst-1, Tst- 2 and Tst-3, respectively, [15] and are toxic to mice, recognizing Na-channels through different modes of action $[19,20]$. Holaday et al. [21] purified butantoxin, a K-channel blocker from the three medically important Tityus species mentioned above. Potassium channel toxins were also predicted in Tityus stigmurus venom using a proteomic approach [22].

Although the scorpion venom repertoire has been extensively investigated by PCR-based methods conducted with cDNA libraries [23-25], this strategy, in addition to cloning, isolation and characterization procedures, is limited by the specificity of the PCR primers used. In recent years, the number of proteomic and transcriptomic analyses performed has increased [26-35], since they are better able to assess venom diversity. Thus, in addition to known venom peptides and proteins, non yet described molecules can also be obtained. Moreover, transcriptomics has the advantage of providing insight into biological processes occurring in venom gland cells.

Previous investigations have used milked scorpion glands to achieve an enriched toxin library [26,27,29,30]; however, only one used a so called "replete" venom gland not actively engaged in regenerating venom [28]. Few scorpion nucleotide sequences are currently deposited in public databases, particularly for the Tityus genus, despite its clinical importance. The present study describes the transcriptomic expression of T. stigmurus scorpion from non-stimulated venom glands, using specimens collected in the urban area of Natal, Brazil.

\section{Results and discussion}

\section{Overview of ESTs from the venom gland of $T$. stigmurus}

After poor-quality sequences were discarded, the remaining 540 high-quality ESTs were used to analyze gene expression profile in the venom gland of T. stigmurus. ESTs were grouped into 153 clusters, 37 corresponding to 'contigs' and 116 to 'singlets' (Additional file 1: ESTs from Tityus stigmurus). As such, these clusters were considered putative unigenes, although some may still represent different segments of the same gene. All sequence data reported in this investigation have been submitted to the public database [GenBank: JK483709 JK483861]. The average length of ESTs was $441 \mathrm{pb}$ and length distribution is shown in Figure 1.

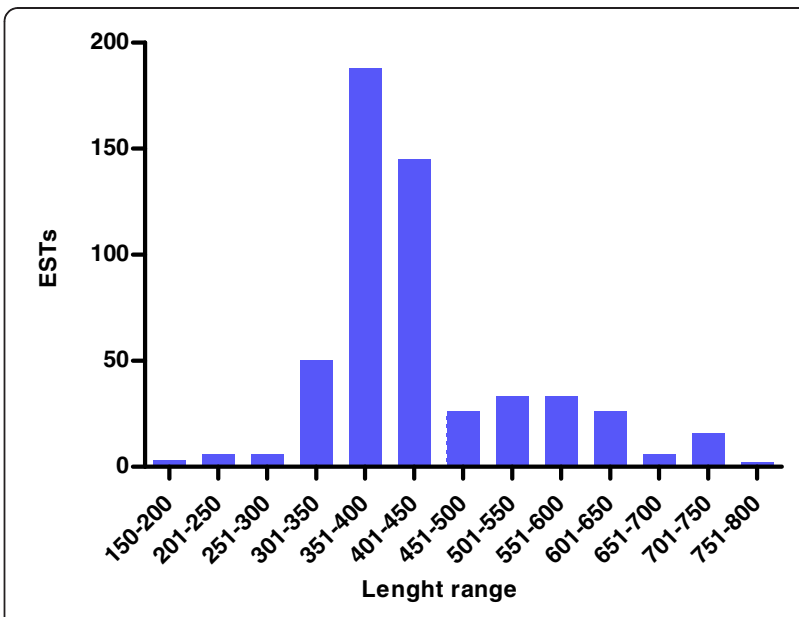

Figure 1 Length distribution of $T$. stigmurus venom gland ESTs. A total of 540 clones were analyzed. Abscissa is the length of sequences in $50 \mathrm{bp}$ intervals, whereas the total number of ESTs for each interval is shown in the Y-coordinate. The average length of ESTs was $441 \mathrm{pb}$.

Sequence clusters were denominated TSTI0001C to TSTI0037C, for clusters with more than one EST, or TSTI0038S to TSTI0153S for those containing only one EST. When compared to data from GenBank and $\mathrm{dbEST}$, we found that of the 153 clusters (540 clones) identified, 113 exhibited significant similarities to known cDNA and protein sequences. This corresponds to 486 clones (90\%); the remaining 54 (10\%) were not identified and defined as "no hit". Six clusters exclusively matching mitochondrial DNAs, mRNAs and ribosomal RNAs were also found and excluded from quantitative analyses.

Clusters were organized into three categories: proteins similar to well-known venom toxins, molecules with probable toxic activity and proteins associated with cellular functions. Figure 2 shows that 'known toxins' represent $41 \%$ of all cDNAs (28 clusters with 222 clones) and $45.87 \%$ of defined sequences, while 'other possible

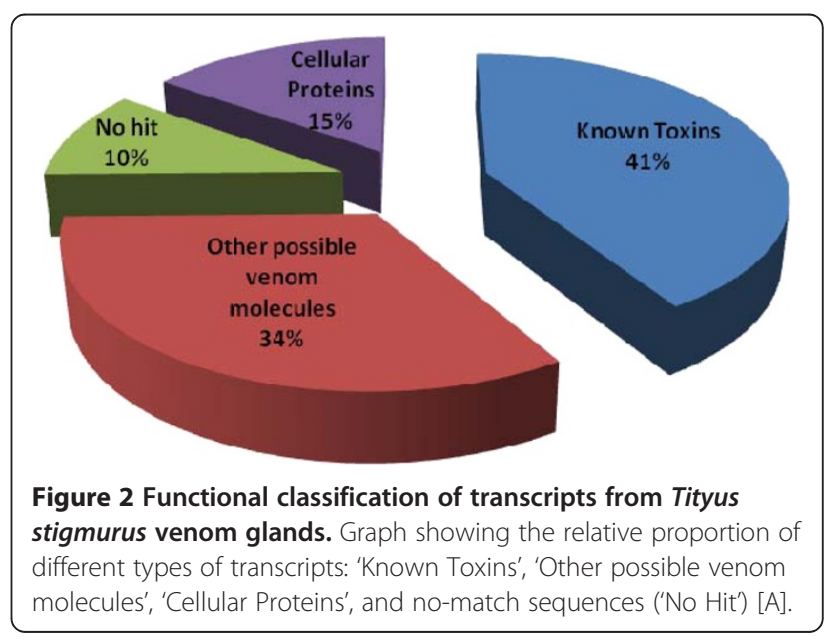


venom molecules' correspond to $34 \%$ of all cDNAs (27 clusters with 180 clones) and $37.2 \%$ of defined sequences. 'Cellular proteins' represent $15.24 \%$ of the total number of clones and $17 \%$ of the matching clones. The remaining sequences are transcripts that do not match database sequences (10\% of total clones, with 34 clusters and 54 clones).

Table 1 shows the twelve most abundant transcript groups, all related to 'known toxins' or 'other possible venom molecules' products, except for the "Unknown Function" and "arginine kinase" groups.

\section{Known toxins}

Six known toxin-related groups were identified in the Tityus stigmurus venom gland transcriptome: $\alpha$-KTX-like, $\beta$-KTX-like, $\alpha$-NaTX-like, $\beta$-NaTX-like, Hypotensins and Antimicrobial Peptides. Figure 3 exhibits the repertoire of known toxins found in this investigation.

\section{Potassium channel toxins ( $\alpha-K T X, \beta-K T X$ )}

Potassium channel toxins have been reported in almost all scorpion species studied. They are 23 to 64 amino acid residues in length and densely packed by three or four disulfide bridges [8]. Ten clusters (48 clones) were identified as putative $\alpha$-KTX toxin precursors, the second most abundant of the 'known toxins'. Two (TSTI0075S and TSTI0109S) were similar to the short toxin structural class found in Tityus serrulatus venom, consisting of TsPep1, TsPep2 and TsPep3 (T. serrulatus peptide 1, 2 and 3) [36]. TSTI0075S and TsPep2 contain 68 amino acid residues and the predicted signal peptide differs in only two amino acids, meaning it may encode the same mature peptide. TSTI0109S has a shorter sequence, with a length of 62 amino acids, and its predicted mature sequence shares $91 \%$ identity with Tst-17

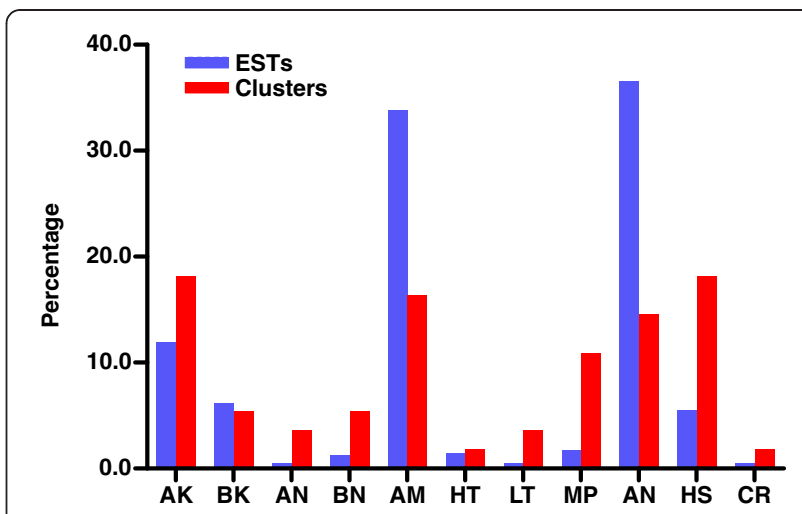

Figure 3 Functional classification of the "Known toxins" and "Other possible venom molecules" categories by relative abundance, considering only these categories. Acronyms are designated as follows: AK, alfa KTX; BK, beta KTX; AN, alfa NaTX; BN, beta NaTX; AM, Antimicrobial peptides; HT, Hypotensins; LT, Lectins; MP, Metalloproteases; AN, Anionic peptides; HS, Hipothetical secreted peptides; CR, Cystein-rich peptides. The blue and gray bars show the classification groups according to EST and cluster abundance, respectively.

(Figure 4) previously recorded in T. stigmurus venom using a proteomic approach [22]. Two other clusters (TSTI0122S, TSTI0140S) exhibited 68\% and 93\% identity with the $T$. costatus toxin $\alpha-K T X ~ 4.5$ [37]. Other cysteine-rich sequences showed homology to alpha-KTX peptides, with TSTI0016C the most representative containing 34 clones. TSTI0016C is $60 \%$ identical to "cysteinerich peptide clone 2", a putative toxin from $T$. costatus [37]. In regard to sequences matching $\beta-\mathrm{KTX}$, we obtained 3 related clusters ( 25 clones), all of which could be aligned to the "orphan" components TcoKIK, TtrKIK, TdiKIK and BmTXK $\beta$ found in T. costatus, T. trivitattus, T. discrepans and Mesobuthus marteensi, respectively

Table 1 Identification of high-abundance transcripts present in $T$. stigmurus venom glands

\begin{tabular}{|c|c|c|c|c|c|}
\hline Groups & $\begin{array}{l}\text { Number } \\
\text { of clusters }\end{array}$ & $\begin{array}{l}\text { Number } \\
\text { of clones }\end{array}$ & $\begin{array}{l}\text { Clones/ } \\
\text { clusters }\end{array}$ & $\%$ of total & Putative identification \\
\hline 1 & 8 & 147 & 18.38 & 27.22 & Anionic peptide* \\
\hline 2 & 9 & 136 & 15.11 & 25.19 & AMP- like* \\
\hline 3 & 10 & 48 & 4.80 & 8.89 & alfa KTX-like* \\
\hline 4 & 3 & 25 & 8.33 & 4.63 & beta KTX-like* \\
\hline 5 & 8 & 20 & 2.50 & 3.70 & hypothetical secreted peptide* \\
\hline 6 & 7 & 8 & 1.14 & 1.48 & Unknown Function ${ }^{1}$ \\
\hline 7 & 2 & 8 & 4.00 & 1.48 & arginine kinase \\
\hline 8 & 6 & 7 & 1.25 & 1.30 & Metalloprotease* \\
\hline 9 & 1 & 6 & 6.00 & 1.11 & Hypotensin* \\
\hline 10 & 3 & 5 & 1.67 & 0.93 & beta NaTX-like* \\
\hline 11 & 2 & 2 & 1.00 & 0.37 & alfa NaTX-like* \\
\hline 12 & 1 & 2 & 2.00 & 0.37 & cystein-rich peptide* \\
\hline
\end{tabular}

The $\left(^{*}\right)$ indicates detection of a putative signal peptide, predicted using the SignalP 3.0 program (http://www.cbs.dtu.dk/services/SignalP/). ${ }^{1}$ Signal peptides were detected in some clusters. 


TSTI0109S
P0C175
P0C8X6

(Figure 5A). These components were assumed to be authentic orthologous genes and denominated as "orphan" since their function is not well defined [38].

TSTI0003C may be a new member of this orthologous genes family, displaying greater similarity to $\beta$-KTX genes from $T$. costatus (gb|Q0GY45) and T. trivitattus (gb|Q0GY42) when compared to the other family members (Figure 5B).

\section{Sodium channel toxins ( $a-\mathrm{NaTX}, \beta$-NaTX)}

The venom of scorpions from the Buthidae family contains abundant sodium channel toxins, in contrast to
non-Buthidae scorpions. These neurotoxins are involved in envenomation lethality $[18,31]$. However, some reports focusing on molecular analysis of the scorpion venom repertoire have proved that variations in venom composition may occur due to uncontrolled external factors, including depletion and environmental conditions [29,39]. In addition, considering the relative number of clusters, low representation of sodium channel toxins in Buthidae scorpions was previously found in the Lychas mucronatus transcriptome, in which sodium toxins accounted for $3.2 \%$ of clusters [29]. This finding is similar to that of our study on Tityus stigmurus

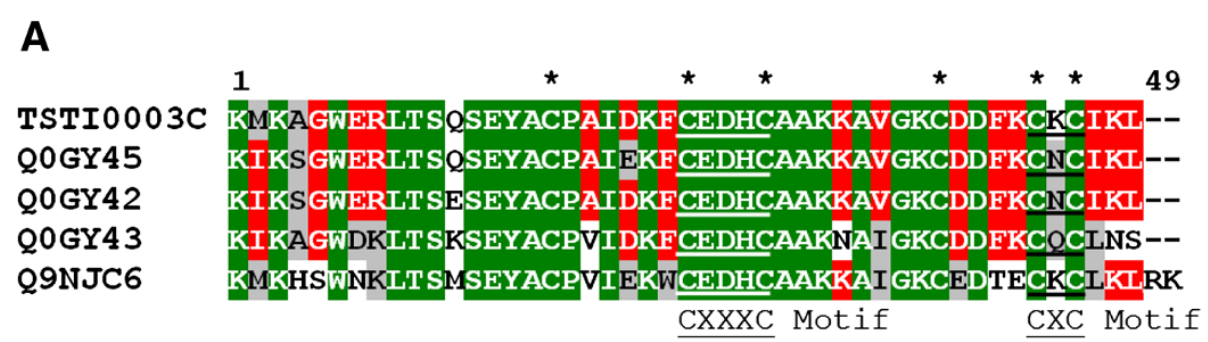

B
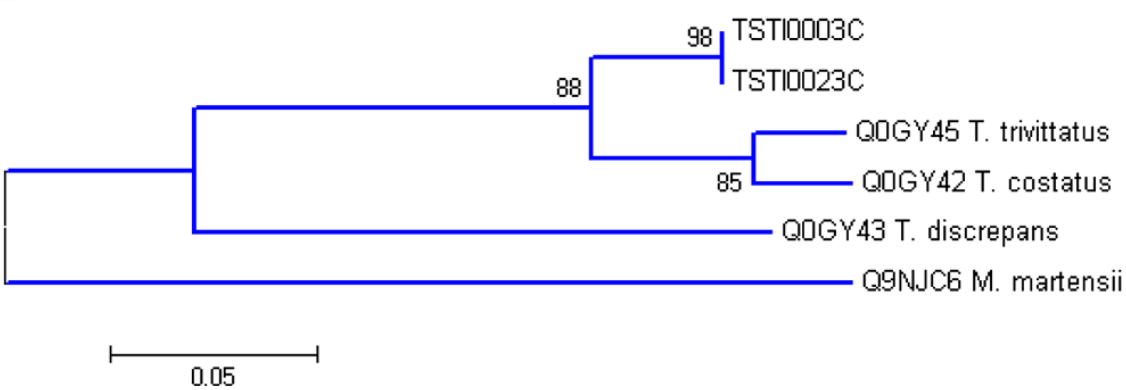

Figure 5 Alignment of the amino acid sequence for TSTI0003C, from T. stigmurus venom glands, with known potassium channel toxins ( $\beta$-KTX). Residues are numbered according to the aligned potassium channel toxins ( $\beta-K T X)$ sequences and dots represent gaps introduced to improve alignment. The putative signal peptide is omitted. Conserved cystein residues are indicated by asterisks. The CXXXC and CXC motifs conserved among scorpion neurotoxins are underlined. Green, red and gray indicate amino acids that are identical, conserved or similar, respectively. The abbreviation and GenBank accession number for the aligned potassium channel toxins sequences are: TtrKIK, Tityus trivitattus potassium channel toxin (Q0GY45); TcoKIK, Tityus costatus potassium channel toxin (Q0GY42); TdiKIK, Tityus discrepans potassium channel toxin (Q0GY43) and BmTXKß, Mesobuthus marteensi potassium channel toxin (Q9NJC6) [A]. Dendogram of $\beta$-KTX peptides sequences from scorpion venoms $[B]$. 
transcriptome, in which we obtained only two clusters ( 2 clones) encoding for $\alpha$-NaTX-like sequences and 3 (5 clones) for $\beta$-NaTX-like sequences (Figure 6). This fact may be associated with lower lethality of Tityus stigmurus human envenoming when compared to Tityus serrulatus accidents.

Another similar case was that of Hottentota judaicus scorpion "resting" venom glands, where sodium channel toxins were underrepresented and the $\alpha \mathrm{NaTx}: \beta \mathrm{NaTx}$ ratio inversed [28]. Sequences matching Tst-1 (TSTI0051S), Tst-2 (TSTI0033C) and Tst-3 (TSTI0151S) were also found in this group.

\section{Hypotensins}

Bradikynin Potentiating Peptides (BPPs), peptides with hypotension properties, have been described in different animal venoms, including snakes, frogs and scorpions [40-43]. These peptides usually inhibit angiotensin converting enzymes (ACEs) and the breakdown of endogenous vasodilator bradykinin, leading to reduced systemic blood pressure [44]. Recently, Verano-Braga [45] discovered a group of BPPs in Tityus serrulatus venom (T. serrulatus Hypotensins: TsHpt-I, TsHpt-II, TsHpt-III and TsHpt IV) containing 24-25 amino acid residues. They display bradykinin-potentiating activity, without ACE inhibition, and their anti-hypertension activity appears to be caused by nitric oxide (NO)-dependent mechanisms. Interestingly, we identified one cluster ( 6 clones) showing high identity with the abovementioned hypotensins in the middle-region. The TSTI0006C cluster encodes a precursor with 72 amino acid residues and a putative 24 amino acid-long signal peptide (Figure 7). It is important to note that pharmacological activity in these peptides seems to be located towards the C-terminal, suggesting a posttranslational modification in this region since the predicted mature peptide has 48 amino acid residues [45].

\section{AMPs (antimicrobial peptides)}

Antimicrobial peptides are commonly found in scorpion transcriptomes $[26-28,30]$. They play an important role in innate immune systems and may depolarize neuronal cells inducing prey immobilization, as well as potentiate the action of other neurotoxins [46]. Surprisingly, AMPs were the most abundant category among toxins and the second when considering the entire transcriptome (136 clones, 9 clusters). High expression levels in AMPs were previously reported in Lychas mucronatus scorpions on Hainan, a hot, humid island in Southern China. These characteristics could cause greater susceptibility to pathogenic microbial infections [29]. Interestingly, a similar climate is found in the city where T. stigmurus specimens were collected. In addition, $T$. stigmurus are frequently found in sewage pipes hunting for prey, mainly cockroaches. It is therefore not coincidence that many envenomation cases occur in bathrooms. Thus, effective defenses are needed in this environment. TSTI0001C is the most representative transcript in this category (Figure 8).

\section{Other possible venom molecules}

Some transcripts found in T. stigmurus venom glands resembled putative molecules with potential toxic activity and were therefore classified as 'other possible venom molecules'. Five groups fit into this category: Lectins, Metalloproteases, Anionic Peptides, Hypothetical Secreted Peptides and Cystein-Rich peptides.

\section{Lectins}

Lectins have not been reported for scorpions in transcriptomic, proteomic or related approaches. As such, to the best of our knowledge, there are no scorpion lectin sequences currently deposited in public databases, although lectins have been isolated from scorpion venom and hemolymph using chromatographic procedures $[47,48]$. Despite the lack of information on lectins in scorpion venoms, they have been studied in other venomous animals, such as fish, snakes and spiders [49-51] and may be involved in innate immunity. Our library contains two clusters (TSTI0068S and TSTI0118S) with arthropod lectin-like sequences.

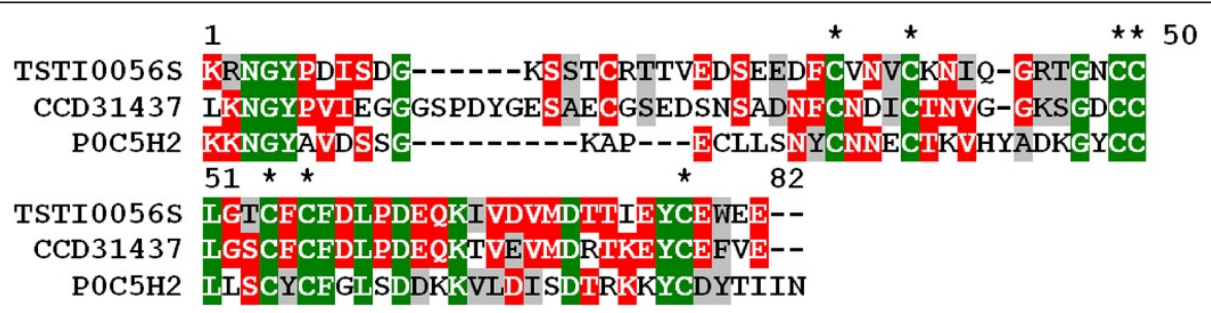

Figure 6 Alignment of the amino acid partial sequence for TSTI0056S, from T. stigmurus venom glands, with known sodium channel toxins ( $\beta$-NaTX). Residues are numbered according to the aligned sodium channel toxins ( $\beta$-NaTX) sequences and dots represent gaps introduced to improve alignment. The putative signal peptide is omitted. Conserved cystein residues are indicated by asterisks. Green, red and gray indicate amino acids that are identical, conserved or similar, respectively. The abbreviation and GenBank accession number for the aligned sodium channel toxins sequences are: Tpa8, Tityus pachyurus, sodium channel toxin (CCD31437); IsomTx2, Isometrus vittatus, potassium channel toxin $(\mathrm{POC} 5 \mathrm{H} 2)$. 


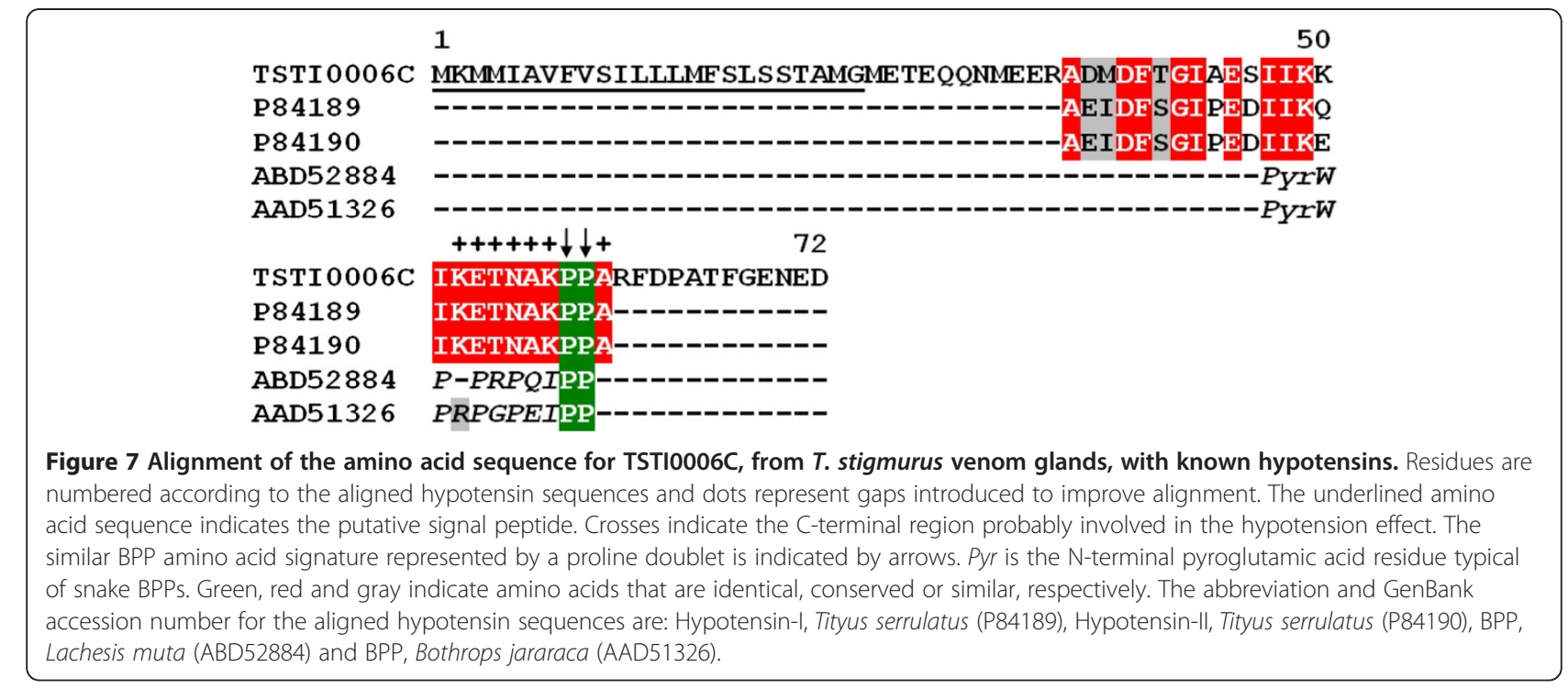

\section{Anionic peptides}

Anionic peptide precursors are molecules with high acidic amino acid content. Unexpectedly, this category exhibits the most expressed transcripts (147 clones and 8 clusters). Anionic peptides have been recorded in both Buthidae and non-Buthidae scorpions [24,29-31,37,52], although they seem much more abundant in the former. Their function remains unclear, but one hypothesis suggests two possible roles: to help balance the $\mathrm{pH}$ value of the venom solution, since most scorpion venom peptides are basic, or to act synergistically with other peptides [24] (Figure 9).

\section{Metalloproteases}

Alhough scorpion venom research has focused primarily on neurotoxic peptides, proteolytic activity has also been described $[53,54]$. Two types of proteases have already been characterized in scorpion venom glands: serineproteases (SPSVs) and metalloproteases $[27,28,55]$. Serine- and metalloproteases were also detected in venom transcriptomic analysis of other animals $[51,56]$. Despite the lack of transcripts similar to SPSVs, metalloproteases are significantly represented by 6 clusters (7 clones). Four of these are similar to antareases, a venom protein from $T$. serrulatus. Antarease is a divalent ion-dependent protease that cleaves vesicle-associated membrane proteins (VAMPs) at specific sites, leading to significant alterations in vesicular transport and secretory mechanisms. This action may be involved in pathogenesis mechanisms, including acute pancreatitis induction [57]. An additional two clusters encode for putative M13 metalloprotease and angiotensin converting enzymes from the Hottentotta Judaicus scorpion.

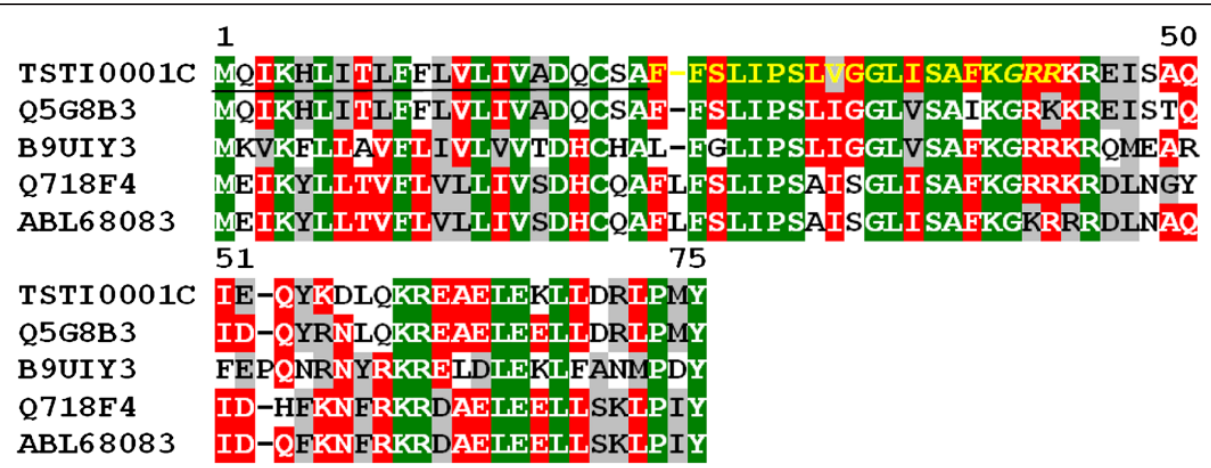

Figure 8 Alignment of the amino acid sequence for TSTI0001C, from T. stigmurus venom glands, with known sequences of antimicrobial peptides. Residues are numbered according to the aligned antimicrobial peptide sequences and dots represent gaps introduced to improve alignment. The underlined amino acids indicate the putative signal peptide. A possibly promature peptide is shown in yellow font and the putative post-translational signal GRR is in italics. Green, red and gray indicate amino acids that are identical, conserved or similar, respectively. The abbreviation and GenBank accession number for aligned antimicrobial peptide sequences are: Tityus costatus antimicrobial peptide (Q5G8B3), Mucroporin, Lychas mucronatus (B9UIY3), Bmkb1, Mesobuthus martensii (Q718F4) and Caerin-2 Mesobuthus eupeus (ABL68083). 


\section{Hypothetical secreted peptides}

Several transcripts (10 clusters, 22 clones) were similar to hypothetical secreted peptides from other scorpions. The function of these peptides is unknown; however, according to our data, some clones appear to be conservative in scorpion and arachnid venom or salivary glands. Further characterization is needed for clones belonging to this category. An interesting finding is the significantly expressed contig TSTI022C (7 clones), showing $91 \%$ identity with a partial mass spectrometry protein sequence (peptide 9797) from a Tityus stigmurus venom proteomic analysis [22]. Another finding is IGFBP (insulin-like growth factor-binding protein) domain containing sequences [TSTI052S, TSTI0064S and TSTI0125S]. IGFBPs modulate the physiological actions of insulinlike growth factors (IGFs) in several types of tissues [58], including tumor cells [59-61]. Other scorpion and insect venom molecules also had IGFBP domains [29,31] (Figure 10).

\section{Cysteine-rich secretory peptides}

Cystein-rich secretory peptides (CRISPs) are widely distributed in the animal, plant and fungal kingdoms, with variable primary sequences [62-64], including different animal venoms $[28,62,65]$. The SCP_CRISP-like domain containing sequence is a cluster with 2 clones (TSTI0017C), similar to other arachnid and insect cysteine-rich peptides. Interestingly, as with helothermine [66], lizard venom CRISPs block $\mathrm{Ca}^{++}$transporting ryanodine receptors, while the opposite action is reported for neurotoxins belonging to the calcin family found in scorpions [67].

The first analysis of a non-Buthidae scorpion resulted in 147 high-quality ESTs, which allowed the authors to examine the molecular repertoire of the venom gland [26]. Similar approaches have been applied with Buthidae and non-Buthidae scorpions species, showing marked differences in diversity and repertoire of toxin-like sequences [68]. The venom components commonly found in transcriptomics are sodium channel toxins, potassium channel toxins, calcines, AMPs, BPPs, phospholipases $\mathrm{A}_{2}$, anionic peptides and glycine-rich peptides. Of these, only calcines, phospholipases $\mathrm{A}_{2}$ and glycine-rich peptides were not found in this study. The main novelty of this investigation is to present some poorly or as yet undescribed transcripts in scorpion venoms such as: lectins, metaloproteases, cystein-rich peptides and hypothetical secreted proteins.

Scorpion venom proteome studies have been previously carried out, although most components have not been sequenced [27,32,33,35]. Thus, a comparative proteomic analysis with other scorpion venoms is difficult to obtain. Nevertheless, the following transcripts match proteins found in Tityus $s p$. venom itself, using either proteomics or isolation and characterization approaches, as follows: TSTI0022C (hypothetical secreted peptide, similar to Peptide 9797, gb|P0C8X1), TSTI0051S (sodium channel toxin, similar to Tst1, gb| P56612), TSTI0033C (sodium channel toxin, similar to Tst2, gb|P68411), TSTI0151S and TSTI0048S (sodium channel toxin, similar to Tst3, gb|P0C8X5), TSTI0109S (potassium channel toxin, similar to Tst-17, gb|P0C8L2), TSTI0140S (potassium channel toxin, similar to Tst26 gb|P0CB56), TSTI0016C (potassium channel toxin, similar to Ts15 gb|P86270), TSTI0075S (potassium channel toxin, similar to TsPep2, gb|P0C175), TSTI0006C (Hypotensin-II, gb|P84190) and some Antareases-like sequences (gb|P86392).

\section{Cellular proteins}

In addition to transcripts predicted to be involved in venom toxicity, there are other housekeeping genes in $T$. stigmurus venom glands. Figure 11 shows the 82 clones (15.24\% of total) found in this study corresponding to 'cellular proteins', most of which are responsible for cellular metabolism (36 clones) and transcription/translation (15 clones). 


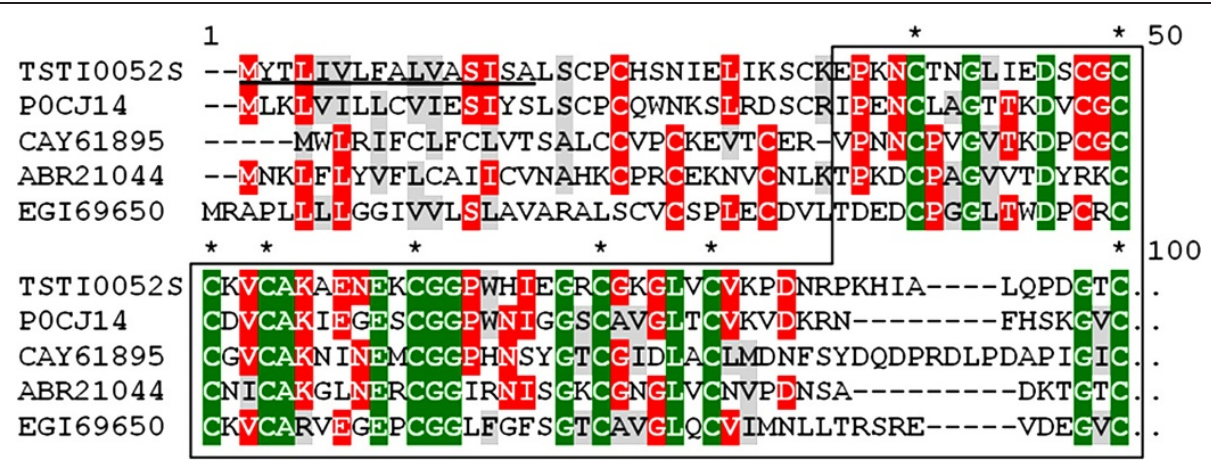

Figure 10 Alignment of the amino acid sequence for TSTI0052S, from T. stigmurus venom glands, with known sequences of IGFBP (insulin-like growth factor-binding protein). Residues are numbered according to aligned IGFBP sequences and dots represent gaps introduced to improve alignment. The underlined amino acids indicate the putative signal peptide. Conserved cystein residues are indicated by asterisks. The IGFBP domain is highlighted by a box. Green, red and gray indicate amino acids that are identical, conserved or similar, respectively. The GenBank accession number for aligned IGFBP sequences are: Lychas mucronatus (POCJ14), Mesobuthus eupeus (CAY61895), Tityus discrepans (ABR21044), Acromyrmex echinatior (EGl69650).

The majority of transcripts involved in 'cellular metabolism' are similar to cytochrome c oxidase (3 clusters/ 12 ESTs), followed by arginine kinase (1 cluster/ 7 ESTs). Clusters TSTI0014C, TSTI0037C and TSTI0065S are similar to cytochrome c oxidase subunits 1 or 2. TSTI0014C resembles cytochrome c oxidase subunit 1 from Centruroides noxius. The terminal oxidase in respiratory chains of eukaryotes and most bacteria, is a multi-chain transmembrane protein located in the inner membrane of mitochondria and the cell membrane of prokaryotes (gb| AY995829.1). In parallel, cluster TSTI0013C (group of 7 ESTs) is similar to arginine kinase (represented in group 8, from Table 1) from Litopenaeus vanname shrimp. Members of this enzyme family play a key role in animals as ATP-buffering systems for cells with high and variable rates of ATP turnover (gb| DQ975203.1).

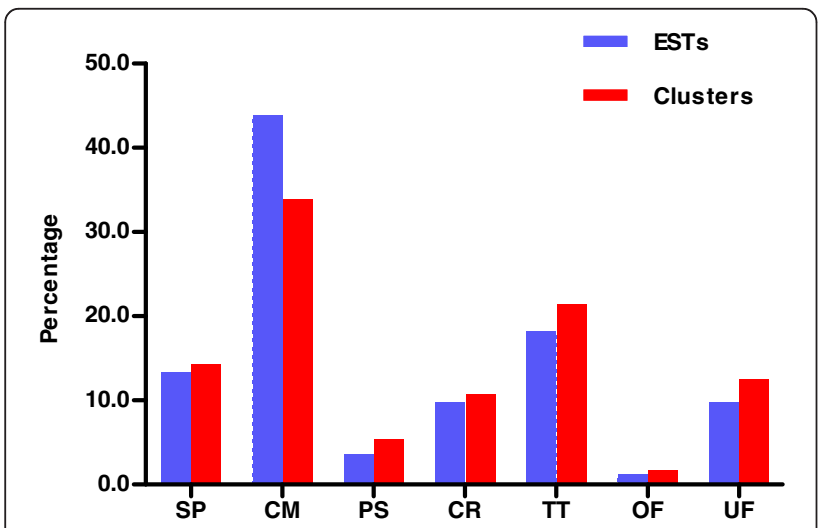

Figure 11 Relative abundance of ESTs coding for cellular proteins. Acronyms are designated as follows: SP, Structural proteins; CM, Cell Metabolism; PS, Processing and Sorting; CR, Cell Regulation; TT, Transcription and Translation; OF, Other Functions; UF, Unknown Functions. The blue and gray bars show the classification groups relative to EST and Cluster abundance, respectively.
The venom gland is an organ specialized in venom production, with almost $75 \%$ of the transcripts 'known' or 'possible' toxins. We can therefore assume that a substantial metabolic expenditure is required for this task, resulting in a natural demand for energy and transcription/translation functions. The next most abundant transcripts were 'structural proteins' (11 clones, 8 clusters) such as actin and myosin. The presence of these transcripts is not surprising, since telson is known to contain compressor muscles, whose function is to press the glands against the cuticle along its exterior lateral and ventral surfaces [1]. Cluster TSTI0018C (group of 3 ESTs) exhibits similarity with myosin light chain 2 from the Avicularia avicularia spider, a $\mathrm{Ca}^{2+}$-binding protein (EF-Hand superfamily) (gb| 3DTP_E).

Other relevant categories were 'cell regulation' (6 clusters/ 8 ESTs), 'processing and sorting' (3 ESTs) and transcripts with unknown functions (7 clusters/ 8 ESTs). In the last, we found 5 clusters matching 'hypothetical proteins' from arachnids (Ixodes scapularis and Tityus discrepans).

Taken together, these results represent important clues for the characterization of cellular and molecular functions in scorpion venom glands. Moreover, the repertoire generated in this approach is relevant in highlighting the transcripts of $T$. stigmurus venom glands, contributing to the international "Genbank" database and allowing subsequent isolation and application of these molecules.

\section{Conclusions}

The present study describes the profile of gene expression present in the venom glands of Tityus stigmurus scorpions using a transcriptomic approach. This profile shows a wide range of structural and functional putative molecules in Tityus stigmurus venom glands. Six known protein types were identified, including 'potassium 
channel' (sub-families $\alpha$ and $\beta$ ) , 'sodium channel' (subfamilies $\alpha$ and $\beta$ ), 'hypotensins' and 'antimicrobial peptides', and five atypical types of venom peptides and proteins, such as 'lectins', 'anionic peptides', 'metalloproteases', 'hypothetical secreted peptides' and 'cystein-rich peptides'. This strategy confirms the highly specialized nature of scorpion venom glands as toxin producers, enabling the description, for the first time, of putative proteins involved in cellular processes relevant to venom gland function of $T$. stigmurus. In particular, transcripts encoding antimicrobial peptides and anionic peptides were the most representative transcripts in this database. The transcriptome of T. stigmurus did not show high expression of sodium channel toxins as one might expect from a Buthidae scorpion, primarily for subfamily $\alpha$. This type of toxin is the most studied among scorpions from the genus Tityus and has often been related to the severity of poisoning. Its absence may be associated to environmental conditions, where more antibacterial defenses may be required than neurotoxins for prey, since food is abundant. It may also be a characteristic of scorpion venom-filled glands in a resting stage.

This database of scorpion molecules described here may be an important resource for the investigation and characterization of proteins or peptides potentially applicable in pharmaceutical research and biotechnology.

\section{Methods}

\section{cDNA library construction}

A cDNA library was constructed from total RNA extracted from four telsons. Specimens were collected in the urban region of Natal, Brazil. The 'total RNA isolation system' of Promega (Madison, WI) was used for RNA isolation. With this material, a full-length cDNA library was prepared using the In-Fusion ${ }^{\text {TM }}$ SMARTer $^{\text {TM }}$ cDNA Library Construction Kit (CLONTECH Lab., Palo Alto, CA). The titre of the non-amplified cDNA library obtained was $2 \times 10^{4} \mathrm{cfu} / \mathrm{mL}$ with $90 \%$ recombinant clones. Reverse transcription used SMARTer II $A$ and 3' SMART CDS Primer II A oligonucleotides. Next, 5' PCR Primer II $A$ was employed for PCR amplification. Resulting cDNAs were bidirectionally cloned in the pSMART2IF plasmid (all components were from the CLONTECH Lab, Palo Alto, CA). Escherichia coli DH10 $\beta$ cells were transformed with cDNA library plasmids and plated on LuriaBertani agarose plates containing $100 \mu \mathrm{g} / \mathrm{mL}$ ampicilin.

\section{DNA sequencing and bioinformatic analyses}

Random clones were grown in antibiotic selective medium for $22 \mathrm{~h}$ and plasmid DNA was isolated using alkaline lysis [69]. DNA was sequenced on an ABI 3100 sequencer, using a BigDye2 kit (Applied Biosystems, Foster City, CA) and the standard M13 reverse primer. In order to extract the high quality sequence region, ESTs were subjected to the Phred program, with a cutoff Phred score of 20 in a window length of 75 bases [70]. Sequences were processed by removing vector, adaptors and E. coli DNA sequences using CrossMatch [71]. High-quality ESTs were assembled into contigs, using the CAP3 program [72] set to combine only those sequences with at least $98 \%$ base identity. To assign annotation to the assembled ESTs (clusters), these sequences were searched against $\mathrm{nr}$ and $\mathrm{nt}$ (E values $<1 \mathrm{e}-05)$ for homologous comparison using BLASTX and BLASTN [73], supported by the Blast2GO [74]. Metadata and bibliographic information, when available, were manually inspected to assign putative functional classification of the cluster. Additionally, proteins coded by the clusters were grouped according to possible participation in the venom. Three categories were established: 'known toxins', 'other possible venom molecules' or 'cellular proteins' for proteins with best hits to well-known scorpion venom toxins, proteins with hits to non-scorpion toxin sequences exhibiting activities compatible with toxic venom action, and other products related to cellular functions without evidence of being toxins, respectively. The presence of conserved domains, using the nr protein database or SMART [75] and Pfam [76], was also used to guide functional attribution. The occurrence of signal peptide was predicted with the SignalP 3.0 program [77], using both neural networks (NN) and hidden Markov models (HMM). A secretory protein was considered when both methods showed a signal peptide according to their default parameters (mean $\mathrm{S}>0.048$ and mean D score $0.43>$ in $\mathrm{NN}$ and signal peptide probability $>0.5$ in HMM).

\section{Alignment and dendogram}

Alignment was conducted with the Vector NTI Suite program (Informax). The dendogram of Figure 4B was created with the neighbor joining method implemented in MEGA5.03 [78].

\section{Additional file}

Additional file 1: ESTs from Tityus stigmurus. Table containing additional information about all the clusters from the scorpion Tityus stigmurus.

\section{Competing interests}

The authors declare they have no competing interests.

\section{Authors' contributions}

DDA performed the cDNA library, conducted bioinformatic analysis and drafted the manuscript. KCS participated in CDNA library and drafted the manuscript. LSK carried out DNA sequencing. LFA-L drafted portions of the manuscript. SRBM drafted portions of the manuscript. AAS-J drafted portions of the manuscript. IdLMJ-d-A performed data processing, bioinformatic analysis and reviewed the manuscript. MdFF-P participated in its design and coordination, in data analyses and drafted the manuscript. All authors read and approved the final manuscript. 


\section{Acknowledgements}

This research was supported by grants from CNPq. MdFF-P, IdLMJ-d-A, KCS, $L F A-L$ and SRBM are researchers from CNPq.

\section{Author details}

${ }^{1}$ Laboratório de Tecnologia e Biotecnologia Farmacêutica, Universidade Federal do Rio Grande do Norte, Av. Gal. Cordeiro de Farias, s/n, CEP 59010-180 Natal, RN, Brazil. 'Laboratório de Biologia Molecular e Genômica, Universidade Federal do Rio Grande do Norte, Natal, RN, Brazil. ${ }^{3}$ Centro de Biotecnologia, Instituto Butantan, Av. Prof. Vital Brazil, 1500, CEP 05503-900 São Paulo, SP, Brazil.

Received: 15 October 2011 Accepted: 27 June 2012 Published: 1 August 2012

\section{References}

1. Polis GA: The biology of scorpions. California: Stanford University Press; 1990

2. Saúde FN (Ed): Book Manual de Diagnóstico e Tratamento de Acidentes por Animais Peçonhentos. City: FUNASA; 2001.

3. Lira-da-Silva RM, Amorim AM, Brazil TK: Poisonous sting by Tityus stigmurus (Scorpiones; Buthidae) in the state of Bahia, Brazil. Rev Soc Bras Med Trop 2000, 33:239-245.

4. Nishikawa AK, Caricati CP, Lima ML, Dos Santos MC, Kipnis TL, Eickstedt VR, Knysak I, Da Silva MH, Higashi HG, Da Silva WD: Antigenic cross-reactivity among the venoms from several species of Brazilian scorpions. Toxicon 1994, 32:989-998.

5. Possani LD, Becerril B, Delepierre M, Tytgat J: Scorpion toxins specific for $\mathrm{Na}+$-channels. Eur J Biochem 1999, 264:287-300.

6. Yu FH, Yarov-Yarovoy V, Gutman GA, Catterall WA: Overview of molecular relationships in the voltage-gated ion channel superfamily. Pharmacol Rev 2005, 57:387-395.

7. de la Vega RC R, Possani LD: Overview of scorpion toxins specific for $\mathrm{Na}+$ channels and related peptides: biodiversity, structure-function relationships and evolution. Toxicon 2005, 46:831-844

8. de la Vega RC R, Possani LD: Current views on scorpion toxins specific for K+-channels. Toxicon 2004, 43:865-875.

9. Valdivia HH, Possani LD: Peptide toxins as probes of ryanodine receptor structure and function. Trends Cardiovasc Med 1998, 8:111-118.

10. Chuang RS, Jaffe H, Cribbs L, Perez-Reyes E, Swartz KJ: Inhibition of T-type voltage-gated calcium channels by a new scorpion toxin. Nat Neurosci 1998, 1:668-674.

11. Olamendi-Portugal T, Garcia BI, Lopez-Gonzalez I, Van Der Walt J, Dyason K, Ulens C, Tytgat J, Felix R, Darszon A, Possani LD: Two new scorpion toxins that target voltage-gated $\mathrm{Ca} 2+$ and $\mathrm{Na}+$ channels. Biochem Biophys Res Commun 2002, 299:562-568.

12. DeBin JA, Maggio JE, Strichartz GR: Purification and characterization of chlorotoxin, a chloride channel ligand from the venom of the scorpion. Am J Physiol 1993, 264:C361-369.

13. Zasloff M: Antimicrobial peptides of multicellular organisms. Nature 2002, 415:389-395.

14. Tan PT, Veeramani A, Srinivasan KN, Ranganathan S, Brusic V: SCORPION2: a database for structure-function analysis of scorpion toxins. Toxicon 2006 , 47:356-363.

15. Becerril B, Corona M, Coronas FI, Zamudio F, Calderon-Aranda ES, Fletcher PL Jr, Martin BM, Possani LD: Toxic peptides and genes encoding toxin gamma of the Brazilian scorpions Tityus bahiensis and Tityus stigmurus. Biochem J 1996, 313(Pt 3):753-760.

16. Becerril B, Marangoni S, Possani LD: Toxins and genes isolated from scorpions of the genus Tityus. Toxicon 1997, 35:821-835.

17. Chavez-Olortegui C, Kalapothakis E, Ferreira AM, Ferreira AP, Diniz CR: Neutralizing capacity of antibodies elicited by a non-toxic protein purified from the venom of the scorpion Tityus serrulatus. Toxicon 1997, 35:213-221.

18. Alvarenga LM, Diniz CR, Granier C, Chavez-Olortegui C: Induction of neutralizing antibodies against Tityus serrulatus scorpion toxins by immunization with a mixture of defined synthetic epitopes. Toxicon 2002, 40:89-95.

19. Lombet A, Lazdunski M: Characterization, solubilization, affinity labeling and purification of the cardiac $\mathrm{Na}+$ channel using Tityus toxin gamma. Eur J Biochem 1984, 141:651-660.
20. Yatani A, Kirsch GE, Possani LD, Brown AM: Effects of New World scorpion toxins on single-channel and whole cell cardiac sodium currents. Am J Physiol 1988, 254:H443-451.

21. Holaday SK Jr, Martin BM, Fletcher PL Jr, Krishna NR: NMR solution structure of butantoxin. Arch Biochem Biophys 2000, 379:18-27.

22. Batista CV, Roman-Gonzalez SA, Salas-Castillo SP, Zamudio FZ Gomez-Lagunas F, Possani LD: Proteomic analysis of the venom from the scorpion Tityus stigmurus: biochemical and physiological comparison with other Tityus species. Comp Biochem Physiol C Toxicol Pharmacol 2007, 146:147-157.

23. Goudet C, Chi CW, Tytgat J: An overview of toxins and genes from the venom of the Asian scorpion Buthus martensi Karsch. Toxicon 2002, 40:1239-1258.

24. Zeng XC, Wang SX, Zhu Y, Zhu SY, Li WX: Identification and functional characterization of novel scorpion venom peptides with no disulfide bridge from Buthus martensii Karsch. Peptides 2004, 25:143-150.

25. Zeng XC, Luo F, Li WX: Molecular dissection of venom from Chinese scorpion Mesobuthus martensii: identification and characterization of four novel disulfide-bridged venom peptides. Peptides 2006, 27:1745-1754

26. Schwartz EF, Diego-Garcia E, Possani LD, de la Vega Rodriguez RC Transcriptome analysis of the venom gland of the Mexican scorpion Hadrurus gertschi (Arachnida: Scorpiones). BMC Genomics 2007, 8:119.

27. Ma Y, Zhao Y, Zhao R, Zhang W, He Y, Wu Y, Cao Z, Guo L, Li W: Molecular diversity of toxic components from the scorpion Heterometrus petersii venom revealed by proteomic and transcriptome analysis. Proteomics 2010, 10:2471-2485.

28. Morgenstern D, Rohde BH, King GF, Tal T, Sher D, Zlotkin E: The tale of a resting gland: transcriptome of a replete venom gland from the scorpion Hottentotta judaicus. Toxicon 2011, 57:695-703.

29. Ruiming Z, Yibao M, Yawen H, Zhiyong D, Yingliang W, Zhijian C, Wenxin L: Comparative venom gland transcriptome analysis of the scorpion Lychas mucronatus reveals intraspecific toxic gene diversity and new venomous components. BMC Genomics 2010, 11:452

30. Ma Y, Zhao R, He Y, Li S, Liu J, Wu Y, Cao Z, Li W: Transcriptome analysis of the venom gland of the scorpion Scorpiops jendeki: implication for the evolution of the scorpion venom arsenal. BMC Genomics 2009, 10:290.

31. D'Suze G, Schwartz EF, Garcia-Gomez Bl, Sevcik C, Possani LD: Molecular cloning and nucleotide sequence analysis of genes from a cDNA library of the scorpion Tityus discrepans. Biochimie 2009, 91:1010-1019.

32. Batista CV, D'Suze G, Gomez-Lagunas F, Zamudio FZ, Encarnacion S, Sevcik C, Possani LD: Proteomic analysis of Tityus discrepans scorpion venom and amino acid sequence of novel toxins. Proteomics 2006, 6:3718-3727.

33. Bringans S, Eriksen S, Kendrick T, Gopalakrishnakone P, Livk A, Lock R, Lipscombe R: Proteomic analysis of the venom of Heterometrus longimanus (Asian black scorpion). Proteomics 2008, 8:1081-1096.

34. Ma Y, He Y, Zhao R, Wu Y, Li W, Cao Z: Extreme diversity of scorpion venom peptides and proteins revealed by transcriptomic analysis: implication for proteome evolution of scorpion venom arsenal. J Proteomics 2012, 75:1563-1576.

35. Diego-Garcia E, Peigneur S, Clynen E, Marien T, Czech L, Schoofs L, Tytgat J: Molecular diversity of the telson and venom components from Pandinus cavimanus (Scorpionidae Latreille 1802): transcriptome, venomics and function. Proteomics 2012, 12:313-328.

36. Pimenta AM, Legros C, Almeida Fde M, Mansuelle $P$, De Lima ME, Bougis PE, Martin-Eauclaire MF: Novel structural class of four disulfide-bridged peptides from Tityus serrulatus venom. Biochem Biophys Res Commun 2003, 301:1086-1092.

37. Diego-Garcia E, Batista CV, Garcia-Gomez BI, Lucas S, Candido DM, GomezLagunas F, Possani LD: The Brazilian scorpion Tityus costatus Karsch: genes, peptides and function. Toxicon 2005, 45:273-283.

38. Diego-Garcia E, Schwartz EF, D'Suze G, Gonzalez SA, Batista CV, Garcia BI, de la Vega RC, Possani LD: Wide phylogenetic distribution of Scorpine and long-chain beta-KTx-like peptides in scorpion venoms: identification of "orphan" components. Peptides 2007, 28:31-37.

39. Pimenta AM, De Marco Almeida F, de Lima ME, Martin-Eauclaire MF, Bougis PE: Individual variability in Tityus serrulatus (Scorpiones, Buthidae) venom elicited by matrix-assisted laser desorption/ionization time-offlight mass spectrometry. Rapid Commun Mass Spectrom 2003, 17:413-418.

40. Ferreira $\mathrm{SH}$ : A bradykinin-potentiating factor (Bpf) present in the venom of bothrops jararca. Br J Pharmacol Chemother 1965, 24:163-169. 
41. Conceicao K, Konno K, de Melo RL, Antoniazzi MM, Jared C, Sciani JM, Conceicao IM, Prezoto BC, de Camargo AC, Pimenta DC: Isolation and characterization of a novel bradykinin potentiating peptide (BPP) from the skin secretion of Phyllomedusa hypochondrialis. Peptides 2007, 28:515-523.

42. Meki AR, Nassar AY, Rochat $H$ : A bradykinin-potentiating peptide (peptide $\mathrm{K} 12$ ) isolated from the venom of Egyptian scorpion Buthus occitanus. Peptides 1995, 16:1359-1365.

43. Junqueira-de-Azevedo IL, Ching AT, Carvalho E, Faria F, Nishiyama MY Jr, Ho PL, Diniz MR: Lachesis muta (Viperidae) cDNAs reveal diverging pit viper molecules and scaffolds typical of cobra (Elapidae) venoms: implications for snake toxin repertoire evolution. Genetics 2006, 173:877-889.

44. Hodgson WC, Isbister GK: The application of toxins and venoms to cardiovascular drug discovery. Curr Opin Pharmacol 2009, 9:173-176.

45. Verano-Braga T, Rocha-Resende C, Silva DM, lanzer D, Martin-Eauclaire MF, Bougis PE, de Lima ME, Santos RA, Pimenta AM: Tityus serrulatus Hypotensins: a new family of peptides from scorpion venom. Biochem Biophys Res Commun 2008, 371:515-520

46. Carballar-Lejarazu R, Rodriguez MH, de la Cruz Hernandez-Hernandez F, Ramos-Castaneda J, Possani LD, Zurita-Ortega M, Reynaud-Garza E, Hernandez-Rivas R, Loukeris T, Lycett G, Lanz-Mendoza H: Recombinant scorpine: a multifunctional antimicrobial peptide with activity against different pathogens. Cell Mol Life Sci 2008, 65:3081-3092.

47. Khoang NA, Berezin BB, Lakhtin VM, lamskov IA: Isolation and some properties of a lectin from the venom of the Vietnamese scorpion Buthus occitanus sp. Prikl Biokhim Mikrobiol 2001, 37:628-632

48. Ahmed H, Anjaneyulu G, Chatterjee BP: Serological characterization of humoral lectin from Heterometrus granulomanus scorpion hemolymph. Dev Comp Immunol 1986, 10:295-304

49. Saraiva TC, Grund LZ, Komegae EN, Ramos AD, Conceicao K, Orii NM Lopes-Ferreira M, Lima C: Nattectin a fish C-type lectin drives Th1 responses in vivo: licenses macrophages to differentiate into cells exhibiting typical DC function. Int Immunopharmacol 2011, 11:1546-1556.

50. Correa-Netto C, Junqueira-de-Azevedo Ide L, Silva DA, Ho PL, Leitao-deAraujo M, Alves ML, Sanz L, Foguel D, Zingali RB, Calvete JJ: Snake venomics and venom gland transcriptomic analysis of Brazilian coral snakes, Micrurus altirostris and M. corallinus. J Proteomics 2011, 74:1795-1809.

51. Fernandes-Pedrosa Mde F, Junqueira-de-Azevedo Ide L, Goncalves-deAndrade RM, Kobashi LS, Almeida DD, Ho PL, Tambourgi DV: Transcriptome analysis of Loxosceles laeta (Araneae, Sicariidae) spider venomous gland using expressed sequence tags. BMC Genomics 2008, 9:279.

52. Luo F, Zeng XC, Hahin R, Cao ZJ, Liu H, Li WX: Genomic organization of four novel nondisulfide-bridged peptides from scorpion Mesobuthus martensii Karsch: gaining insight into evolutionary mechanism. Peptides 2005, 26:2427-2433.

53. Tan NH, Ponnudurai G: Comparative study of the enzymatic, hemorrhagic, procoagulant and anticoagulant activities of some anima venoms. Comp Biochem Physiol C 1992, 103:299-302.

54. Almeida FM, Pimenta AM, De Figueiredo SG, Santoro MM, Martin-Eauclaire MF, Diniz CR, De Lima ME: Enzymes with gelatinolytic activity can be found in Tityus bahiensis and Tityus serrulatus venoms. Toxicon 2002, 40:1041-1045

55. Gao R, Zhang Y, Gopalakrishnakone P: Purification and N-terminal sequence of a serine proteinase-like protein (BMK-CBP) from the venom of the Chinese scorpion (Buthus martensii Karsch). Toxicon 2008, 52:348-353.

56. Leao LI, Ho PL, Junqueira-de-Azevedo IL: Transcriptomic basis for an antiserum against Micrurus corallinus (coral snake) venom. BMC Genomics 2009, 10:112

57. Fletcher PL Jr, Fletcher MD, Weninger K, Anderson TE, Martin BM: Vesicleassociated membrane protein (VAMP) cleavage by a new metalloprotease from the Brazilian scorpion Tityus serrulatus. J Biol Chem 2010, 285:7405-7416.

58. Maki RG: Small is beautiful: insulin-like growth factors and their role in growth, development, and cancer. J Clin Oncol 2010, 28:4985-4995.

59. Heidegger I, Pircher A, Klocker H, Massoner P: Targeting the insulin-like growth factor network in cancer therapy. Cancer Biol Ther 2011, 11:701-707.

60. Pen A, Durocher Y, Slinn J, Rukhlova M, Charlebois C, Stanimirovic DB, Moreno MJ: Insulin-like growth factor binding protein 7 exhibits tumor suppressive and vessel stabilization properties in U87MG and T98G glioblastoma cell lines. Cancer Biol Ther 2011, 12:634-646.

61. Azar WJ, Azar SH, Higgins S, Hu JF, Hoffman AR, Newgreen DF, Werther GA, Russo VC: IGFBP-2 enhances VEGF gene promoter activity and consequent promotion of angiogenesis by neuroblastoma cells. Endocrinology 2011, 152:3332-3342.

62. Milne TJ, Abbenante G, Tyndall JD, Halliday J, Lewis RJ: Isolation and characterization of a cone snail protease with homology to CRISP proteins of the pathogenesis-related protein superfamily. J Biol Chem 2003, 278:31105-31110.

63. Roberts KP, Ensrud KM, Wooters JL, Nolan MA, Johnston DS, Hamilton DW: Epididymal secreted protein Crisp-1 and sperm function. Mol Cell Endocrinol 2006, 250:122-127.

64. Gibbs GM, O'Bryan MK: Cysteine rich secretory proteins in reproduction and venom. Soc Reprod Fertil Suppl 2007, 65:261-267.

65. Muller L, Vogel M, Stadler M, Truffer R, Rohner E, Stadler BM: Sensitization to wasp venom does not induce autoantibodies leading to infertility. Mol Immunol 2008, 45:3775-3785.

66. Morrissette J, Kratzschmar J, Haendler B, el-Hayek R, Mochca-Morales J, Martin BM, Patel JR, Moss RL, Schleuning WD, Coronado R, et al: Primary structure and properties of helothermine, a peptide toxin that blocks ryanodine receptors. Biophys J 1995, 68:2280-2288.

67. Norton RS, McDonough SI: Peptides targeting voltage-gated calcium channels. Curr Pharm Des 2008, 14:2480-2491.

68. Quintero-Hernandez V, Ortiz E, Rendon-Anaya M, Schwartz EF, Becerril B, Corzo G, Possani LD: Scorpion and spider venom peptides: gene cloning and peptide expression. Toxicon 2011, 58:644-663.

69. Junqueira-de-Azevedo Ide L, Ho PL: A survey of gene expression and diversity in the venom glands of the pitviper snake Bothrops insularis through the generation of expressed sequence tags (ESTs). Gene 2002, 299:279-291.

70. Ashburner M, Ball CA, Blake JA, Botstein D, Butler H, Cherry JM, Davis AP, Dolinski K, Dwight SS, Eppig JT, et al: Gene ontology: tool for the unification of biology. The Gene Ontology Consortium. Nat Genet 2000, 25:25-29.

71. Martinez F, Munoz-Garay C, Gurrola G, Darszon A, Possani LD, Becerril B: Site directed mutants of Noxiustoxin reveal specific interactions with potassium channels. FEBS Lett 1998, 429:381-384.

72. Huang X, Madan A: CAP3: a DNA sequence assembly program. Genome Res 1999, 9:868-877.

73. Altschul SF, Madden TL, Schaffer AA, Zhang J, Zhang Z, Miller W, Lipman DJ: Gapped BLAST and PSI-BLAST: a new generation of protein database search programs. Nucleic Acids Res 1997, 25:3389-3402

74. Conesa A, Gotz S, Garcia-Gomez JM, Terol J, Talon M, Robles M: Blast2GO: a universal tool for annotation, visualization and analysis in functional genomics research. Bioinformatics 2005, 21:3674-3676.

75. Schultz J, Copley RR, Doerks T, Ponting CP, Bork P: SMART: a web-based tool for the study of genetically mobile domains. Nucleic Acids Res 2000, 28:231-234

76. Bateman A, Birney E, Durbin R, Eddy SR, Howe KL, Sonnhammer EL: The Pfam protein families database. Nucleic Acids Res 2000, 28:263-266

77. Bendtsen JD, Nielsen H, von Heijne G, Brunak S: Improved prediction of signal peptides: SignalP 3.0. J Mol Biol 2004, 340:783-795.

78. Tamura K, Peterson D, Peterson N, Stecher G, Nei M, Kumar S: MEGA5: molecular evolutionary genetics analysis using maximum likelihood, evolutionary distance, and maximum parsimony methods. Mol Biol Evol 2011, 28:2731-2739.

doi:10.1186/1471-2164-13-362

Cite this article as: Almeida et al:: Profiling the resting venom gland of the scorpion Tityus stigmurus through a transcriptomic survey. BMC Genomics 2012 13:362. 